\title{
Influence of climate variability and human activities on stream flow variation in the past 50 years in Taoer River, Northeast China
}

\author{
ZHANG Kai ${ }^{1,2}$, "LI Lijuan ${ }^{1}$, BAI Peng ${ }^{1}$, LI Jiuyi ${ }^{3}$, LIU Yumei ${ }^{4}$ \\ 1. Key Laboratory of Water Cycle \& Related Land Surface Processes, Institute of Geographic Sciences and \\ Natural Resources Research, CAS, Beijing 100101, China; \\ 2. University of Chinese Academy of Sciences, Beijing 100049, China; \\ 3. Institute of Geographic Sciences and Natural Resources Research, CAS, Beijing 100101, China; \\ 4. Suzhou University of Science and Technology, Suzhou 215009, Jiangsu, China
}

\begin{abstract}
Taoer River Basin, which is located in the west of Northeast China, is an agropastoral ecotone. In recent years, the hydrological cycle and water resources have changed significantly with the deterioration of the environment. Many water problems such as river blanking, wetland shrinking and salinization have occurred in this region. All of these phenomena were directly caused by changes in stream flow under climate variability and human activities. In light of the situation, the impact of climate variability and human activities on stream flow should be identified immediately to identify the primary driving factors of basin hydrological processes. To achieve this, statistical tests were applied to identify trends in variation and catastrophe points in mean annual stream flow from 1961 to 2011. A runoff sensitive coefficients method and a SIMHYD model were applied to assess the impacts of stream flow variation. The following conclusions were found: 1) The years 1985 and 2000 were confirmed to be catastrophe points in the stream flow series. Thus, the study period could be divided into three periods, from 1961 to 1985 (Period I), 1986 to 2000 (Period II) and 2001 to 2011 (Period III). 2) Mean annual observed stream flow was $31.54 \mathrm{~mm}$ in Period I, then increased to 65.60 $\mathrm{mm}$ in Period II and decreased to $2.92 \mathrm{~mm}$ in Period III. 3) Using runoff sensitive coefficients, the contribution of climate variability was $41.93 \%$ and $43.14 \%$ of the increase in stream flow during Periods II and III, suggesting that the contribution of human activities to the increase was $58.07 \%$ and $56.86 \%$, respectively. 4) Climate variability accounted for $42.57 \%$ and $44.30 \%$ of the decrease in stream flow, while human activities accounted for $57.43 \%$ and $55.70 \%$ of the decrease, according to the SIMHYD model. 5) In comparison of these two methods, the primary driving factors of stream flow variation could be considered to be human activities, which contributed about $15 \%$ more than climate variability. It is hoped that these conclusions will benefit future regional planning and sustainable development.
\end{abstract}

Keywords: influence; stream flow variation; climate variability; human activities; Taoer River

Received: 2016-01-29 Accepted: 2016-09-30

Foundation: National Natural Science Foundation of China, No.91547114, No.41201568, No.41201572

Author: Zhang Kai (1987-), PhD Candidate, specialized in hydrology and water resources. E-mail: Kevin76581@gmail.com

*Corresponding author: Li Lijuan (1961-), PhD and Professor, specialized in hydrology and water resources.

E-mail: 1ilj@igsnrr.ac.cn 


\section{Introduction}

The changing environment due to climate variability and human activities could influence hydrological processes, which are complex (Marengo et al., 1998; Schulze, 2000; Tomer and Schilling, 2009; Zhang et al., 2010). With the deterioration of water resources and increasing consumption of global water resources, the study of the impact of climate variability and human activities on hydrology has been of great interest in hydrological science (Vorosmarty et al., 2000; Kang et al., 2004; Scanlon et al., 2007). Many studies have pointed out that global warming could intensify global hydrological processes (Brutsaert and Parlange, 1998; Zhang et al., 2003; Batisani, 2011). Specific to the regional scale, the impact of climate variability on steam flow variation needs to be investigated under each local climate scenario. Land use changes due to human activities and agricultural development can also affect stream flow (Calder, 1993). Climate variability, such as changes in precipitation and evapotranspiration, and increasing temperatures, could cause great variations in regional hydrological processes (Arnell and Reynard, 1996; Li et al., 2010; Wang and Hejazi, 2011; Ma et al., 2015). The effects of climate variability on stream flow in basins across Australia that were simulated by a hydrological model using long term climate data and future climate variability scenarios showed that changes in precipitation could result in enormous variations in stream flow, including both decrease and increase (Chiew et al., 1995; Chiew and McMahon, 2002). A study in North America found that changes in precipitation resulted in up to double the percentage variations in stream flow. Compared with precipitation, temperature changes were only mildly correlated with stream flow variations (Najjar, 1999). Human activities, such as land use/change, water intake, and water transfer projections play vital roles in the temporal and spatial changes of the hydrologic cycle, especially in stream flow variation. (Costa et al., 2003; Li et al., 2007a; Elfert and Bormann, 2010). For example, afforestation could lead to decreases in stream flow, and irrigation can also influence stream flow (Bosch and Hewlett, 1982; Huang and Zhang, 2004; Mu et al., 2007). These activities can not only alter landscape patterns, which affect stream flow processes, but also directly affect the quantity of stream flow. Generally speaking, human activities could affect stream flow in two ways. Some activities (i.e. water intake and water transfer projections) could directly affect stream flow and water resources variation. A study of the Middle Yellow River found that the contribution of direct human activities was about $3 \%$ to $5 \%$ during the past 50 years (Liang et al., 2013). However, stream flow variation influenced by direct activities could show different results in different regions. Changes in landscape patterns could affect stream flows through flow regime processes, such as flood frequency, base flow and mean annual stream flow discharge (Costa et al., 2003; Brath et al., 2006; Wang et al., 2006). Many empirical methods have been used to identify the impacts of those variations that were caused by climate variability and human activities (Zhan and Yu, 1994). But general conclusions could not be applied to all basins based on these empirical studies. Statistical methods (i.e. Mann-Kendall test, Yamamoto test and moving $t$-test) have been proposed to identify variation trends and distinguish between the contributions of climate variability and human activities in a catchment stream flow (Li et al., 2009; Zhang and Lu, 2009). Due to the limited temporal scale and lack of physical mechanisms, hydrological models have been applied to analyze the responses of stream flow processes. However, the results of model simulations have many uncertainties that are caused by model structures, parameters and spatial 
scales (Li et al., 2007b). In order to improve the accuracy of these studies, two methods in particular have been used to quantify and compare the impacts of climate variability and human activities on stream flow (Xu and Vandewiele, 1995; Yates, 1996; Jothityangkoon, 2001; Hu et al., 2012).

The Taoer River flows through Xing'an League and Baicheng City before flowing into the Nenjiang River. The Taoer River Basin, which is the largest watershed on the right bank of the Nenjiang River, has played a very important role in grain production of Northeast China. Due to its semi-arid and semi-humid climatic characteristics, the basin is very sensitive to climate variability and human activities. Between 1961 and 2011, human activities changed this region significantly. The total population of the two municipalities increased from 1.5 million to 3.9 million. The GDP of the region, where agricultural production is the dominant industry, reached 868 billion yuan in 2011. Since the 1960s, the underlying surface of this region has been dramatically altered by extensive development for agriculture and population growth. Especially after the 1980s, large areas of forestland, grassland and wetland have been reclaimed to increase grain yield. In order to achieve the goals of the food production plan of Jilin Province, upland areas were transformed to paddies in suitable irrigation districts. By 2011, the area of cultivated land was $35 \%$ of the whole basin, with grassland decreases by $34 \%$ and forestland decreases by $21 \%$ over the basin. More and more cultivated land has become artificially irrigated. Many water conservation projects were also created to ensure continued grain production, such as the Chaersen reservoir project completed in 1989 and the water diversion project from Nenjiang River to Baicheng City that was completed in 2011. In addition, in the wake of urban sprawl and population expansion, water consumption has been increasingly intensified in the region. Under these conditions, many eco-environmental problems such as river blanking, wetland shrinking, desertification and salinization have developed (Liang, 2008). Secondary salinization of the land has increased more than tenfold from the 1950s, and river blanking has already been reported over a 10-year period since the 1990s (Jiang, 2007). All of these phenomena revealed that the study area was environmentally vulnerable (Zhao, 1999). In light of this situation, the impacts of climate variability and human activities on stream flow should be identified immediately. Many studies have described the influence of changing environments on stream flow variations in the Nenjiang River basin of Northeast China. The results found slight decreasing trends in precipitation and remarkable temperature increases over the last 50 years (Ren et al., 2000; Luan et al., 2007). Therefore, those variations caused a decrease in stream flow in the Nenjiang River basin (Tang et al., 2009). With respect to the Taoer River, there have been fewer studies in recent decades. Liang and Li studied the changing trends in temperature, evaporation, precipitation, and stream flow. They found that from 1960 to 2000, temperature increased by $0.305^{\circ} \mathrm{C}$ per decade and potential evaporation increased by $4.127 \mathrm{~mm}$ per decade (Liang, 2008; Liang et al., 2010). The contribution of climate variability and human activities were about 45\% and 55\%, respectively, between 1960 and 2000 (Li et al., 2010). However, studies rarely mentioned the variation of stream flow after 2000 , so new features and stream flow variation patterns since then should be researched and discussed.

The goal of this study was to continue to inspect the variation and annual stream flow trends, and to verify the contributions of climate variability and human activities to stream flow variation in the Taoer River Basin based on the new data series. It is hoped that the re- 
sults of this study will provide scientific evidence for sustainable development strategies for basins in this region, and benefit future regional exploitation.

\section{Study area}

The Taoer River Basin, which covers an area of about $41,600 \mathrm{~km}^{2}$, is located in the western part of the Song-Nen Plain in Northeast China at $45^{\circ} 6^{\prime}-47^{\circ} 12^{\prime} \mathrm{N}$ and $117^{\circ} 18^{\prime}-124^{\circ} 6^{\prime} \mathrm{E}$. The river begins southeast of the Da Xing'an Mountains and flows into the Yueliangpao Reservoir, which eventually empties into the Nenjiang River (Figure 1). The length of the main channel is $563 \mathrm{~km}$ with an average slope of $1.52 \%$. The west of the basin is the upper reach of the river, with a semi-humid continental monsoon climate and a topography made up of mountains and hills, while the eastern part of the river is the lower range with a semi-arid continental monsoon climate and plains topography. Precipitation increases from east to west, while the evaporation decreases from east to west.

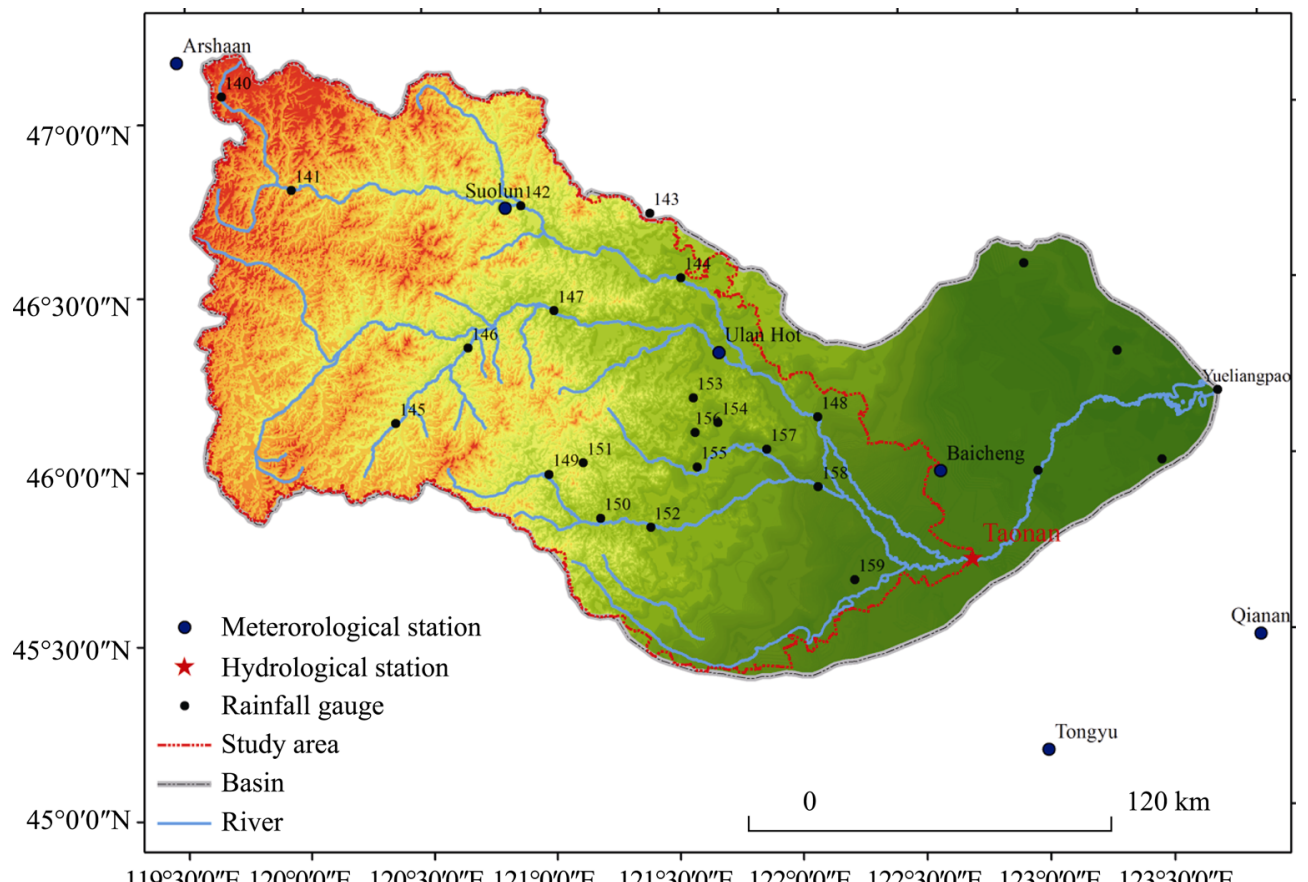

$119^{\circ} 30^{\prime} 0^{\prime \prime} \mathrm{E} 120^{\circ} 0^{\prime} 0^{\prime \prime} \mathrm{E} \quad 120^{\circ} 30^{\prime} 0^{\prime \prime} \mathrm{E} 121^{\circ} 0^{\prime} 0^{\prime \prime} \mathrm{E} \quad 121^{\circ} 30^{\prime} 0^{\prime \prime} \mathrm{E} \quad 122^{\circ} 0^{\prime} 0^{\prime \prime} \mathrm{E} \quad 122^{\circ} 30^{\prime} 0^{\prime \prime} \mathrm{E} \quad 123^{\circ} 0^{\prime} 0^{\prime \prime} \mathrm{E} \quad 123^{\circ} 30^{\prime} 0^{\prime \prime} \mathrm{E}$

Figure 1 Map of the whole basin and the study area

The mean annual precipitation of the study area is about $379 \mathrm{~mm}$, typically occurring during the summer months. Precipitation from June to September accounts for $83 \%$ of the total annual precipitation. About $72 \%$ of the total annual stream flow is generated during the same period. The mean pan evaporation was about 1200 to $1500 \mathrm{~mm}$, which is four times higher than the precipitation from 1961 to 2011.

Because the lower reaches of the basin are comprised of plains and wetlands, stream flow is very low with a low average velocity (Li et al., 2010), and return flow could even occur during the dry season. Furthermore, there is no continuous historical data for Yueliangpao, 
which is the last control station for the basin. Because of those limitations, the lower reach of the river was not included in our study, and only the upper and middle reaches were selected, which cover an area of $27200 \mathrm{~km}^{2}$.

\section{Data description and processing}

\subsection{Data description}

Daily stream flow, precipitation and meteorological data were used in this study. The daily stream flow data were obtained from the Taonan hydrological station. Daily precipitation data were obtained from the Song-Liao Water Resources Commission (SLWRC). Daily meteorological data were obtained from the National Meteorological Information Center (NMIC). 20 rainfall stations and 6 meteorological stations were chosen for the study for the timeframe between January 1, 1961 and December 31, 2011. The daily meteorological data included longitude, latitude, mean daily temperatures $(T)$, maximum and minimum temperatures $\left(T_{\max }\right.$ and $\left.T_{\min }\right)$, daily precipitation $(P)$, mean wind speed $(V)$, daily vapor pressure $(H)$ and daily sunshine hours $(N)$. All stations are listed in Table 1.

Table 1 Summary of rainfall and meteorological gauging stations

\begin{tabular}{cll||ccc||ccc}
\hline ID & Station & Attribute & ID & \multicolumn{1}{c|}{ Station } & Attribute & ID & Station & Attribute \\
\hline 140 & Bailang & rainfall & 149 & Shuangcheng & rainfall & 158 & Wuben & rainfall \\
141 & Wuchagou & rainfall & 150 & Liuhu & rainfall & 159 & Xinlitun & rainfall \\
142 & Suolun & rainfall & 151 & Xieli & rainfall & $/$ & Arshaan & meteorological \\
143 & Minzhu & rainfall & 152 & Gaojiatun & rainfall & $/$ & Suolun & meteorological \\
144 & Cha'ershen & rainfall & 153 & Hulitu & rainfall & $/$ & Ulan Hot & meteorological \\
145 & Fuxingtun & rainfall & 154 & Yongde & rainfall & $/$ & Baicheng & meteorological \\
146 & Alide'er & rainfall & 155 & Nongye & rainfall & $/$ & Tongyu & meteorological \\
147 & Dashizhai & rainfall & 156 & Wanbao & rainfall & $/$ & Qian'an & meteorological \\
148 & Zhenxi & rainfall & 157 & Najin & rainfall & $/$ & Taonan & hydrological \\
\hline
\end{tabular}

\subsection{Data processing}

A total of 18627 data values for each station, which were obtained from the rainfall stations, were used to calculate mean daily precipitation within the selected regions. Using a Thiessen Polygon Method, the regional mean daily precipitation could be obtained. Meanwhile, a total of 18627 data values for each station that were obtained from the meteorological stations were used to calculate daily potential evapotranspiration $\left(E_{0}\right)$ based on the Penman-Monteith method recommended by FAO (Liang et al., 2010). The equation can be written as:

$$
E_{0}=\frac{0.408 \Delta R_{n}+\gamma \frac{900}{T+273} V\left(e_{s}-e_{a}\right)}{\Delta+\gamma(1+0.34 \mathrm{~V})}
$$

where $E_{0}$ is daily potential evapotranspiration $(\mathrm{mm} / \mathrm{d}) ; R_{n}$ is net radiation $\left(\mathrm{MJ} /\left(\mathrm{m}^{2} \cdot \mathrm{d}\right)\right) ; T$ is mean daily temperature $\left({ }^{\circ} \mathrm{C}\right) ; V$ is the wind speed $(\mathrm{m} / \mathrm{s}) ; e_{s}-e_{a}$ is the saturation vapor pres- 
sure deficit $(\mathrm{kPa}) ; \Delta$ is the slope of vapor pressure curve $\left(\mathrm{kPa} /{ }^{\circ} \mathrm{C}\right)$; and $\gamma$ is the psychrometric constant $\left(\mathrm{kPa} /{ }^{\circ} \mathrm{C}\right)$. All the variables in the equation above can be found in Chapter 3 of FAO Paper 56 (Allen et al., 1998). Similarly, the daily potential evapotranspiration from the 6 meteorological stations can be spatially averaged using the Thiessen Polygon Method to get the regional mean daily potential evapotranspiration.

\section{Methodology}

\subsection{Catastrophe point detection with statistical analysis}

(1) Mann-Kendall statistical test

To estimate the temporal trend of mean annual stream flow and detect catastrophe points in the Taoer River, the non-parametric Mann-Kendall (Mann, 1945; Kendall, 1948) test was applied. The M-K test has many robust advantages for dealing with non-normally distributed data, and has been extensively applied to identify eminence change trends in a hydro-climatic time series (Mitchell et al., 1966; Yue and Wang, 2002; Liu et al., 2008; Liang et al., 2010). In this study, we used the ordinal rank statistic from the M-K test that was proposed by Sneyers (Sneyers, 1975). A random data sequence was generated that was composed of $x_{1}, x_{2}, \cdots, x_{n}$, and every term in the rank was independent with same probability. For the elements whose values exceeded $x_{i}$ in the sequence, they were calculated as $m_{i}$. The M-K rank statistic $d_{k}$ could be defined under the null hypothesis of no trend as

$$
d_{k}=\sum_{i=1}^{k} m_{i} \quad(2 \leqslant k \leqslant n)
$$

And the sequence is assumed to be normally distributed with random independence. The mean value and variance can be computed as:

$$
\begin{gathered}
d_{k}=E\left(d_{k}\right)=k(k-1) / 4 \\
\bar{\sigma} d_{k}^{2}=\operatorname{VAR}\left(d_{k}\right)=k(k-1)(2 k+5) / 72
\end{gathered}
$$

The positive sequence of this test statistic can be normalized as $U_{k}$, which could be defined as:

$$
U_{k}=\frac{d_{k}-E\left(d_{k}\right)}{\sqrt{\operatorname{VAR}\left(d_{k}\right)}} \quad(2 \leqslant k \leqslant n)
$$

If the standard normal probability $\operatorname{Prob}\left(|z|>\left|U_{k}\right|\right)>\alpha(k=1,2, \cdots, n)$ has a significance level of $\alpha$, the null hypothesis of no trend would be eliminated (Serrano et al., 1999). In a graphical curve of the sequence as $U F$, the positive sequence trend would increase when $U_{k}>0$ and decrease when $U_{k}<0$.

The reversed data sequence could be calculated as $U_{k}^{*}$ by the same method. Setting another sequence $U_{k}^{\prime}=-U_{k}^{*}$ as the backward sequence of the reversed sequence, the graphical curve could be indicated in the same graph as $U B$. The intersection points of $U F$ and $U B$ located between their confidence intervals could be considered to be the occurrence time of mutations.

(2) Moving $t$-test

The moving $t$-test is widely used to distinguish the difference between the means of two random data series. Setting an $i$ th sample series as the target sequence, it can be divided into 
subsets by given constants $n_{1}$ and $n_{2}$. The values of the statistic $i$ th can be calculated as:

$$
t=\frac{\bar{x}_{1}-\bar{x}_{2}}{\sqrt{\frac{n_{1} s_{1}^{2}-n_{2} s_{2}^{2}}{n_{1}+n_{2}-2} \times\left(\frac{1}{n_{1}}+\frac{1}{n_{2}}\right)}}
$$

where $\bar{x}_{i}, S_{i}^{2}$ and $n_{i}$ are the average, variance and length of the sequence, respectively. Given a significance level of $\alpha$, if the inequality $|t|>t_{\alpha / 2}$ holds, the null hypothesis of there being no difference between the series could be eliminated. Thus, extreme values in the sequence curve, plotted based on values of $t$, indicate an abrupt change in the data series. Further details about this method can be found in the relevant literatures (Fu et al., 1992; Wei, 1999). In this study, $n_{1}=n_{2}=10$ was set to distinguish the different stream flow periods.

By combining these two methods, change points of stream flow can be confirmed and the time series of this study can be divided into different sub-periods. The first period is considered to be the benchmark period, which means that climate variability and human activities are in an initial stage and changes of the environment are small. The following periods are regarded as variety periods in which climate characteristics and human activities uniquely and significantly influence stream flow.

\subsection{Method of estimating climate variability impacts on stream flow}

For a given catchment, it is assumed that the changing environment that affects stream flow can only be divided into two parts; climate variability and human activities. Thus, the total change in observed mean annual stream flow $\left(\Delta Q_{T}\right)$ can be calculated as:

$$
\Delta Q_{T}=\Delta Q_{C}+\Delta Q_{H}
$$

where $\Delta Q_{C}$ is the variation in stream flow due to climate variability effects and $\Delta Q_{H}$ represents the effect of human activities.

Because it has been observed for a long time in the Taoer River Basin, changes in basin water storage can be reasonably assumed to be 0 . The water energy balance equation can be expressed as:

$$
P=E+Q
$$

where $P$ refers to total precipitation, $E$ is total evapotranspiration and $Q$ is total stream flow. Budyko (1974) argued that by using the mean potential evapotranspiration and mean precipitation of the basin, mean annual actual evapotranspiration could be calculated. Following this hypothesis, Zhang et al. $(2001,2008)$ proposed an experiential equation over 250 basins for which the long term mean evapotranspiration can be estimated as:

$$
F(\Phi)=\frac{E}{P}=\frac{1+\omega \Phi}{1+\omega \Phi+(\Phi)^{-1}}
$$

where $\Phi$ is the aridity index $\left(\Phi=E_{0} / P\right), E_{0}$ is potential evapotranspiration, and $\omega$ is a fitting coefficient related to any underlying surface such as vegetation and soil types. Based on previous research, the coefficient can be set to 1.14 (Li et al., 2010).

Climate variability could influence precipitation and potential evapotranspiration of the basin, which are considered to be important factors related to stream flow formation (Dooge et al., 1999). The effects on stream flow can be evaluated (Milly and Dunne, 2002) as:

$$
\Delta Q_{c}=\frac{\partial Q}{\partial P} \Delta P+\frac{\partial Q}{\partial E_{0}} \Delta E_{0}
$$


where $\Delta Q_{c}$ is stream flow variation, $\Delta P$ and $\Delta E_{0}$ are precipitation variation and potential evapotranspiration variation, respectively. $\partial Q / \partial P$ and $\partial Q / \partial E_{0}$ are runoff sensitive coefficients for precipitation and potential evapotranspiration, which can be calculated as:

$$
\begin{gathered}
\frac{\partial Q}{\partial P}=1-F(\Phi)+F(\Phi) \times F^{\prime}(\Phi) \\
\frac{\partial Q}{\partial E_{0}}=-F^{\prime}(\Phi)
\end{gathered}
$$

\subsection{SIMHYD Model simulation}

The SIMHYD model has been successfully applied in over 300 semi-arid and semi-humid catchments in Australia and America, and also been shown to be an effective method for simulating hydrological processes in China (Wang et al., 2008; Vaze and Teng, 2011; Liang et al., 2013). It is a lumped conceptual hydrological model with daily scale, which requires daily rainfall $(P)$ and regional mean potential evapotranspiration $\left(E_{0}\right)$ data to estimate stream flow.

In the SIMHYD model, rainfall fills the interception store first and then becomes excess runoff after the infiltration process. Excess rainfall could be converted into saturation excess runoff, groundwater stores and soil moisture stores. Thus, stream flow would be composed of infiltration excess runoff, saturation excess runoff and base flow (generated by groundwater stores). More information about the model structure and algorithms can be found in Chiew et al.'s studies (Chiew et al., 2002, 2009).

For the observed data in the study, the Nash-Sutcliffe Efficiency Coefficient (NSE) of stream flow can be applied to evaluate the SIMHYD model (Nash and Sutcliffe, 1970). Another fitting test index can be used to calculate the Water Balance Error (WBE) (Liang et al., 2013). NSE and WBE can be expressed mathematically as:

$$
\begin{gathered}
N S E=1-\frac{\sum_{i=1}^{n}\left(Q_{o, i}-Q_{s, i}\right)^{2}}{\sum_{i=1}^{n}\left(Q_{o, i}-\overline{Q_{o}}\right)^{2}} \\
\operatorname{WEB}(\%)=100 \times\left(\frac{\sum_{i=1}^{n} Q_{s, i}-\sum_{i=1}^{n} Q_{o, i}}{\sum_{i=1}^{n} Q_{o, i}}\right)
\end{gathered}
$$

where $Q_{o, i}$ is the observed stream flow and $Q_{s, i}$ is the simulated stream flow. $\overline{Q_{o}}$ is the mean observed stream flow. Then the model can be optimized while maximizing the NSE and minimizing the WEB as much as possible.

\section{Results}

\subsection{Catastrophe point determination}

The moving $t$-test was applied to identify catastrophe points and changing stream flow trends in this study. Figure 2 shows that by setting given constants $n_{1}=n_{2}=10$, two catastro- 
phe points for the observed mean annual stream flow can be estimated for the years 1985 and 2000, with a level of significance of $0.01(P<0.01)$. But when the constants were set to be $n_{1}=n_{2}=5$ in the test, there was no change point during the 1961 to 2011 time period at the same level of significance $(P<0.01)$.

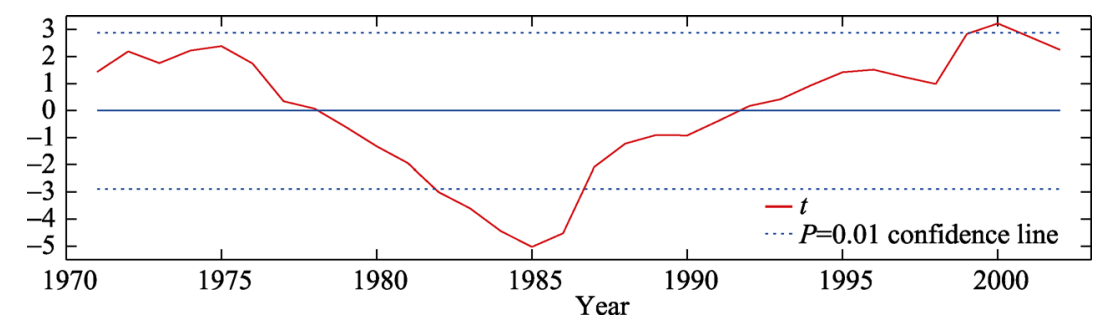

Figure 2 Moving $t$-test of mean annual observed stream flow from 1961 to $2011\left(n_{1}=n_{2}=10\right)$

Because there was no significant result when $n_{1}=n_{2}=5$ was set, another method was applied to identify catastrophe points in the stream flow trend. Prior studies suggested that the Mann-Kendall method could complement the results from the moving $t$-test (Fu and Wang, 1992; Liang, 2008). First, the year 2000, identified by the moving $t$-test, was accepted as the stage divide point. The time series in this study was divided into two periods (i.e. 1961-2000 and 2001-2011). During the period 1961-2000, the M-K test showed that the catastrophe point was the year 1985 at a typical significance level of $0.05(\mathrm{P}<0.05)$; a significant upward trend was also confirmed (Figure 3a). Therefore, it is clear that the year 1985 could be considered as a catastrophe point in the stream flow trend between 1961 and 2000 in the Taoer River Basin.
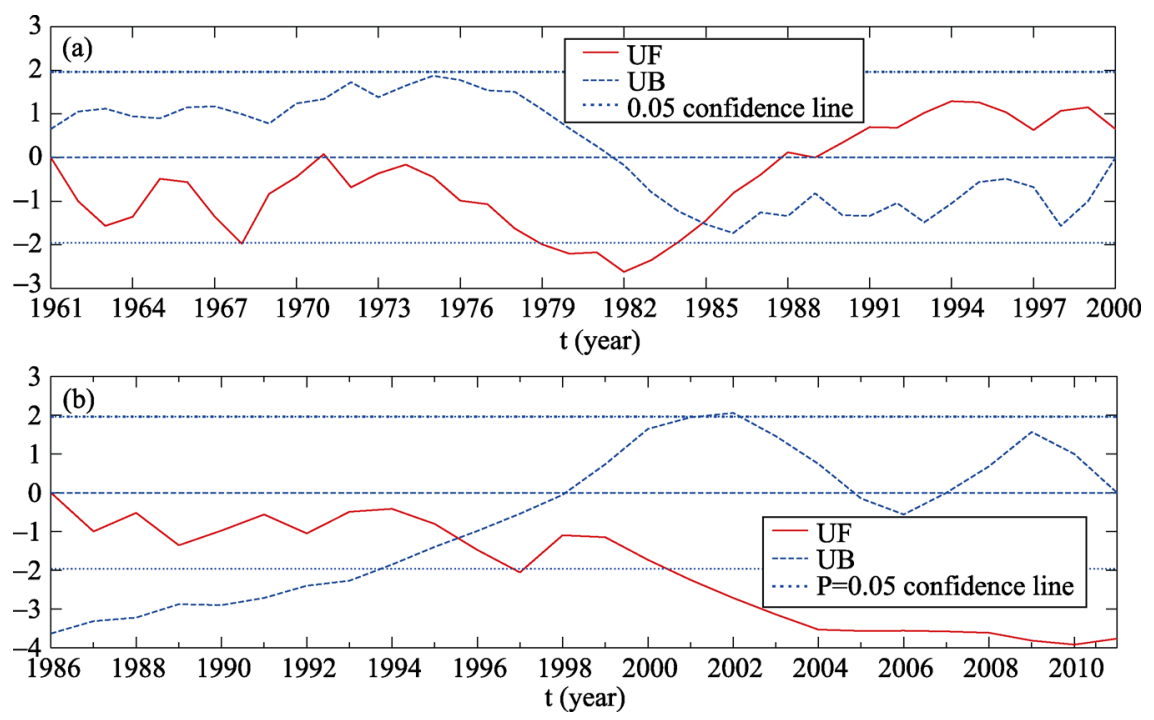

Figure 3 Mann-Kendall test of mean annual observed stream flow from 1961 to 2000 (a) and from 1986 to 2011 (b)

The year 1985, identified by the moving $t$-test, was accepted as a breakpoint in the study time series. The time series was divided into two periods (i.e. 1961-1985 and 1986-2011). 
During the period 1986-2011, the M-K test showed that the catastrophe point was 1996 $(\mathrm{P}<0.05)$ with a significant downward trend (Figure $3 \mathrm{~b}$ ). But the observed stream flows from 1997 to 2000 were much higher than the following years. The features of stream flow were obviously different after the year 2000. If the change point had been chosen to be 1996, the features of the observed stream flow during the last period would have been confused. Compared with the results from the moving $t$-test, it is more reasonable to confirm the second catastrophe point as the year 2000.

According to the results of above analysis, the study time series can be divided into three sub-periods: Period I (1961-1985) (i.e. the natural benchmark period), Period II (1986-2000) (i.e. the first variation period), and Period III (2001-2011) (i.e. the second variation period).

\subsection{Changes in stream flow and precipitation}

The annual observed stream flow and variation trend from 1961 to 2011 is shown in Figure 4. The driest period took place between 2002 and 2004, during which time the observed stream flow could not be measured and the river had zero flow. The most humid year was 1998, when a severe flood occurred in the entire Songhua River Basin and the annual stream flow soared to a high level of $223.38 \mathrm{~mm}$.

According to Figure 4, the mean annual stream flow in Period I was $31.54 \mathrm{~mm}$, increasing to $65.60 \mathrm{~mm}$ from in Period II and then decreasing to $2.92 \mathrm{~mm}$ in Period III. Compared with Period I, the mean annual stream flow increased about $34.06 \mathrm{~mm}$ in Period II and then decreased about $28.62 \mathrm{~mm}$ in Period III. The relative variation between Periods I and II was about $107.99 \%$ and $-90.74 \%$ between Periods I and III. Variations in mean annual precipitation were also noted, with the mean annual precipitation in Period I at $398.42 \mathrm{~mm}$, increasing to $446.55 \mathrm{~mm}$ in the second period and then decreasing to $370.97 \mathrm{~mm}$ in the last period. Compared with Period I, the relative variation was about $12.08 \%$ in Period II and $-6.89 \%$, in Period III.
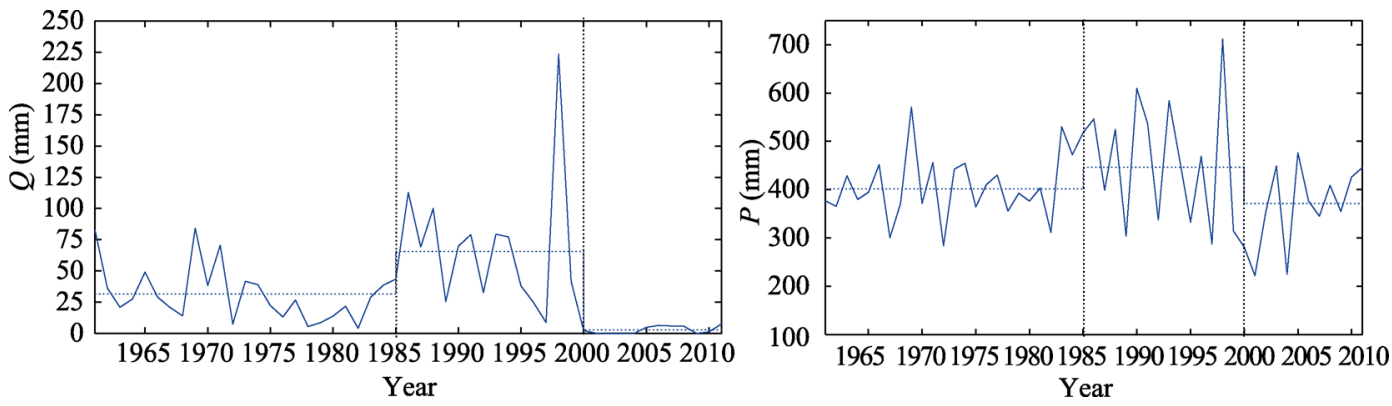

Figure 4 Variation of mean annual observed stream flow $(Q)$ and variation of annual precipitation $(P)$ in Taoer River Basin from 1961 to 2011 (The mean values of each period are represented by horizontal dotted lines.)

\subsection{Effects of climate variability and human activities}

(1) Evaluation of stream flow variation using the runoff sensitive coefficients

Calculated by Equations (8) and (10), the result of the runoff sensitive coefficients $\partial Q / \partial P$ and $\partial Q / \partial E_{0}$ were 0.313 and -0.221 , respectively. According to Equation (9), it indicated that every $100 \mathrm{~mm}$ increase in precipitation $(P)$ would result in a $31.3 \mathrm{~mm}$ increase in stream flow, while every $100 \mathrm{~mm}$ increase in potential evapotranspiration $\left(E_{0}\right)$ would result in a 
$22.1 \mathrm{~mm}$ decrease in stream flow. Table 2 shows that an increase of $48.13 \mathrm{~mm}$ in $P$ during Period II (1986-2000) could lead to a $15.06 \mathrm{~mm}$ increase in stream flow, while a $3.53 \mathrm{~mm}$ increase in $E_{0}$ could lead to a $0.78 \mathrm{~mm}$ decrease in stream flow. Therefore, the effects of climatic variation resulted in an increase of $14.28 \mathrm{~mm}$ for annual stream flow (i.e. $\Delta Q_{C}$ ), accounting for $41.93 \%$ of the total increase. The other $58.07 \%$ of increase in mean annual observed stream flow should be attributed to human activities. Similarly, in Period III (2001-2011), a decrease of $27.45 \mathrm{~mm}$ in $P$ could lead to a $8.59 \mathrm{~mm}$ decrease in stream flow, while a $16.99 \mathrm{~mm}$ increase in $E_{0}$ could lead to a decrease of $3.76 \mathrm{~mm}$ in stream flow, accounting for a total decrease of $43.15 \%$ in annual observed stream flow. Human activities contributed to a decrease of $56.85 \%$ in stream flow during that period. Therefore, the effects of human activities on stream flow contributed about $15 \%$ more than climate variability. Human activities and climate variability could both be considered as primary factors in the variation in stream flow.

Table 2 Effects of climate variability and human activities on stream flow in the Taoer River estimated by runoff sensitive coefficients ${ }^{*}$

\begin{tabular}{cccccccccc}
\hline Period & $Q(\mathrm{~mm})$ & $\Delta Q(\mathrm{~mm})$ & $\Delta P(\mathrm{~mm})$ & $\Delta E_{0}(\mathrm{~mm})$ & \multicolumn{3}{c}{$\Delta Q_{C}$} & \multicolumn{2}{c}{$\Delta Q_{H}$} \\
\hline I & 31.54 & - & - & - & - & - & & \\
II & 65.60 & 34.06 & 48.13 & 3.53 & 14.28 & 41.93 & 19.78 & 58.07 \\
III & 2.92 & -28.62 & -27.45 & 16.99 & -12.35 & -43.14 & -16.27 & -56.86 \\
\hline
\end{tabular}

* Periods I, II and III refer to the sub-periods of 1961-1985, 1986-2000, and 2001-2011, respectively. $Q$ is the mean annual observed stream flow, $\Delta Q$ is the variation in annual stream flow between Periods II/III and Period I. $\Delta P$ and $\Delta E_{0}$ indicate variations of mean annual precipitation and mean annual potential evapotranspiration, respectively. $\Delta Q_{C}$ and $\Delta Q_{H}$ are the variations of stream flow affected by climate variability and human activities, respectively.

\section{(2) Evaluation of stream flow variation using the SIMHYD Model}

The steps for modelling daily hydrological processes with the SIMHYD Model can be divided into the calibration stage and the simulation stage. First, the model was calibrated and validated for the natural benchmark period, which was divided into a warm-up period, a calibration period and a validation period. Second, the calibrated SIMHYD model with same model parameters as the natural benchmark period was applied to simulate stream flow for the variation periods. The results for each period represented the effects of indirect human activities.

For this study, the model was applied for Period I as the "natural benchmark period", in which the years of 1961-1963, 1964-1970, and 1971-1985 were used to represent the warm-up period, calibration period and validation period, respectively. Figure 5 shows the simulated and observed stream flows for Period I. After adjusting the model several times, the optimum stage of the model finally emerged. The NSE and WBE for the model were calculated as 0.736 and $-2.36 \%$ during the validation period, respectively, while the results were 0.796 and $6.89 \%$ during the validation period, respectively. Then the data in Periods II and III were simulated in the calibrated SIMHYD model to calculate the stream flow for each period. Figure 6 shows the simulated and observed stream flows from 1961 to 2011.

The simulated stream flows were $32.48 \mathrm{~mm}, 46.48 \mathrm{~mm}$ and $19.80 \mathrm{~mm}$ for Periods I, II, and III, respectively (Table 3 ). Compared with Period I, the effects of climate variability on stream flow $\left(\Delta Q_{C}\right)$ and the effects of human activities in stream flow $\left(\Delta Q_{H}\right)$ were $16.44 \mathrm{~mm}$ 
and $17.62 \mathrm{~mm}$ in Period II. The contribution of $\Delta Q_{C}$ and $\Delta Q_{H}$ were $42.57 \%$ and $57.43 \%$, respectively. In Period III, $\Delta Q_{C}$ and $\Delta Q_{H}$ were $-12.68 \mathrm{~mm}$ and $-15.94 \mathrm{~mm}$, which meant climate variability resulted in a decrease of $44.30 \%$ in stream flow, while human activities contributed to a decrease of $55.70 \%$ in stream flow.

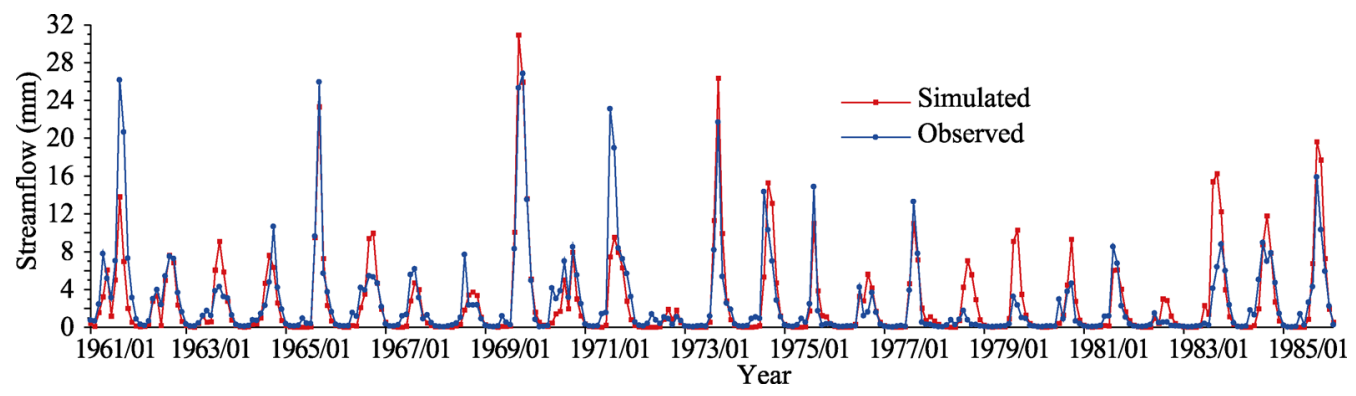

Figure 5 Simulated and observed stream flow during 1961-1985 in the Taoer River (at the monthly time scale)

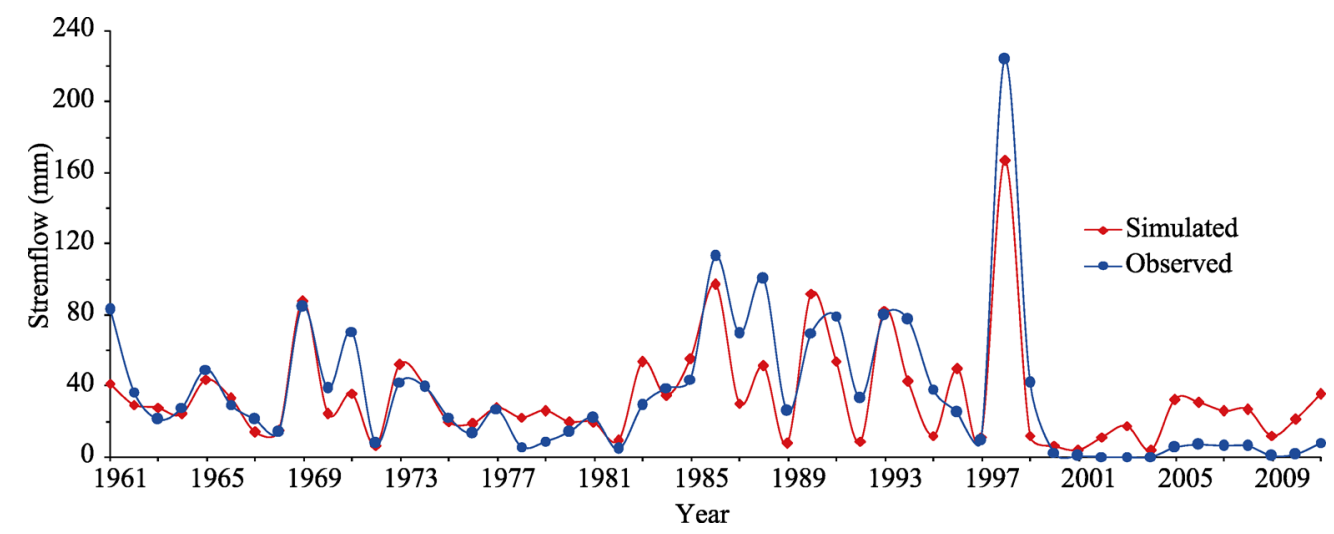

Figure 6 Simulated and observed mean annual stream flows during 1961-2011 in the Taoer River

Table 3 Effects of climate variability and human activities on stream flow in the Taoer River estimated using the SIMHYD model ${ }^{*}$

\begin{tabular}{|c|c|c|c|c|c|c|c|}
\hline \multirow{2}{*}{ Period } & \multirow{2}{*}{$Q(\mathrm{~mm})$} & \multirow{2}{*}{$\Delta Q(\mathrm{~mm})$} & \multirow{2}{*}{$Q_{S}(\mathrm{~mm})$} & \multicolumn{2}{|c|}{$\Delta Q_{C}$} & \multicolumn{2}{|c|}{$\Delta Q_{H}$} \\
\hline & & & & $(\mathrm{mm})$ & $\%$ & $(\mathrm{~mm})$ & $\%$ \\
\hline I & 31.54 & - & 32.48 & - & - & - & - \\
\hline II & 65.60 & 34.06 & 46.98 & 14.50 & 42.57 & 20.06 & 57.43 \\
\hline III & 2.92 & -28.62 & 19.80 & -12.68 & -44.30 & -15.94 & -55.70 \\
\hline
\end{tabular}

* Periods I, II and III refer to sub-periods of 1961-1985, 1986-2000, and 2001-2011, respectively. $Q$ is the mean annual observed stream flow, $Q_{s}$ is the mean simulated annual stream flow and $\Delta Q$ is the variation of annual stream flow in Periods II and III compared with Period I. $\Delta Q_{C}$ and $\Delta Q_{H}$ are the stream flow variations influenced by climate variability and human activities, respectively.

\section{Discussion}

\subsection{Comparative analysis of the two methods for evaluating stream flow}

In this study, the effects of climate variability and human activities on stream flow were dis- 
tinguished by two different methods. The runoff sensitive coefficient method was a statistical method that should be executed at yearly timescales only. The SIMHYD model was a physical model method in which the hydrological processes could be simulated using daily or monthly scale data. However, the results of the two methods for estimating the effects of climate variability and human activities on stream flow variation were quite similar. The effect of climate variability was $14.28 \mathrm{~mm}$ using the runoff sensitive coefficient method for Period II (1986-2000), and it was $16.44 \mathrm{~mm}$ when simulated by the SIMHYD model. In Period III (2001-2011), using the runoff sensitive coefficient method, the effect of climate variability on stream flow was $-12.35 \mathrm{~mm}$. When simulated by the SIMHYD model, the result was $-11.74 \mathrm{~mm}$. The two methods above had similar results, suggesting that the estimation techniques used in this study are credible.

\subsection{Human activities}

Human activities can refer to land use change, water conservation measures and other human activities. In the 20th century, land use and land cover has changed significantly, and the effects of land salinization and desertification are severe. Wetland degradation and deterioration of the regional water environment have become increasingly prominent (Liang, 2008). One of the worst salinization areas in China is distributed throughout the eastern part of the Taoer River Basin, which accounts for about $40 \%$ of the whole basin (Zhang and Lin, 1999; Liang et al., 2010). Therefore, in the most recent decade under national policy interventions, many alkali-saline areas and upland fields have been converted into paddy fields. The paddy fields that had accounted for $0.7 \%$ of the total basin in the $1970 \mathrm{~s}$ and $2.7 \%$ in 2000 , increased to about $6 \%$ of the total basin.

In addition, water conservation measures, water intake and other water consumption activities could directly affect basin stream flow characteristics. Establishing an effective and reliable method to identify the direct and indirect effects of human activities should be the next step in our studies.

\subsection{Uncertainties}

There are many uncertainties that are derived from using these two different methods in this study. Firstly, in estimating the stream flow effects of climate variability with the runoff sensitive coefficient method, the timescale was yearly and could not be analyzed at a shorter timescales (i.e. daily or monthly). However, the relationship between precipitation and runoff is very intricate and cannot be considered to be the same process even during different months of one year. In this case, it could cause some uncertainties in the estimation results. Secondly, when estimating the effects of climate variability by the hydrological model method (SIMHYD), the result was also influenced by parameter uncertainties within the model. The WBE of the model in simulating the variations of stream flow for the calibration and validation periods was about $-2.36 \%$ and $6.89 \%$, respectively, a conscious error in the study. But when compared with the variations due to climate variability and human activities, it is a much smaller factor for the total variability. The estimated results of the two methods were also similar to each other. Therefore, these conclusions should not be disregarded because of uncertainties in the simulation. Lastly, climate variability and human activities were expected to evolve independently of the two methods in this study. However, they were not 
totally independent. In fact, many human activities at large scales, such as land use/cover change, would have had large changes on the underlying surface of the basin. Those activities could affect the impact of the study area's local climate on evaporation and runoff processes. The contribution of the underlying surface variation on evaporation and runoff processes should be further studied to distinguish between the effects of climate variability and human activities more clearly.

\section{Conclusions}

This study examined stream flow variation of the Taoer River from 1961 to 2011. A summary of the results is as follows: 1) Statistical tests showed that the years 1985 and 2000 could be two typical catastrophe points in the study period for mean observed stream flow. Thus the study period can be identified into three sub-periods between 1961 and 2011. 2) Mean annual observed stream flow was $31.54 \mathrm{~mm}$ in Period I (1961-1985), which increased to $65.60 \mathrm{~mm}$ in Period II (1986-2000) and decreased to $2.92 \mathrm{~mm}$ in Period III (2001-2011). 3) The results of the runoff sensitive coefficients method indicated that climate variability contributed $41.93 \%$ of the increase in stream flow during Period II and $43.14 \%$ of the decrease in Period III, while human activities contributed $58.07 \%$ and $56.86 \%$ of the increase during Period II and decrease in Period III, respectively. 4) When simulated using the SIMHYD model, climate variability accounted for $42.57 \%$ of the decrease in stream flow in Period II and $44.30 \%$ in Period III, while human activities were responsible for $57.43 \%$ and $55.70 \%$ of decreases during Periods II and III, respectively. 5) Compared with the results from the runoff sensitive coefficients method and the SIMHYD model method, the contribution of human activities was about $15 \%$ higher than that of climate variability in both methods. This suggests that human activities could be considered to be primary factors when it comes to stream flow variation.

\section{References}

Allen R G, Pereira L S, Raes D et al., 1998. Crop Evapotranspiration-Guidelines for computing crop water requirements-FAO Irrigation and Drainage Paper 56. FAO, Rome 300(9): D05109.

Arnell N W, Reynard N S, 1996. The effects of climate change due to global warming on river flows in Great Britain. Journal of Hydrology, 183(3/4): 397-424.

Batisani N, 2011. Spatio-temporal ephemeral streamflow as influenced by climate variability in Botswana. Journal of Geographical Sciences, 21(3): 417-428.

Birsan M V, Molnar P, Burlando P et al., 2005. Streamflow trends in Switzerland. Journal of Hydrology, 314(1): 312-329.

Brath A, Montanari A, Moretti G, 2006. Assessing the effect on flood frequency of land use change via hydrological simulation (with uncertainty). Journal of Hydrology, 324(1): 141-153.

Bosch J M, Hewlett J D, 1982. A review of catchment experiments to determine the effect of vegetation changes on water yield and evapotranspiration. Journal of Hydrology, 55(1): 3-23.

Brutsaert W, Parlange M B, 1998. Hydrologic cycle explains the evaporation paradox. Nature 396(6706): 30.

Budyko M I, 1974. Climate and Life. San Diego, CA: Academic.

Calder I R, 1993. Hydrologic effects of land-use change. In: Maidment (ed.), Handbook of Hydrology. New York: McCraw-Hill Inc.

Chiew F, McMahon T A, 2002. Modelling the impacts of climate change on Australian stream flow. Hydrological Processes, 16(6): 1235-1245.

Chiew F, Peel M, Western A et al., 2002. Application and testing of the simple rainfall-runoff model SIMHYD. In: Sign V P, Frevert D K (ed.). Mathematical Models of Small Watershed Hydrology and Applications. Littleton: 
Water Resources Publications, 335-367.

Chiew F, Teng J, Vaze J et al., 2009. Estimating climate change impact on runoff across southeast Australia: Method, results, and implications of the modeling method. Water Resources Research, 45(10). doi: 10.1029/ 2008WR007338.

Chiew F, Whetton P H, McMahon T A et al., 1995. Simulation of the impacts of climate change on runoff and soil moisture in Australian catchments. Journal of Hydrology, 167(1): 121-147.

Costa M H, Botta A, Cardille J A, 2003. Effects of large-scale changes in land cover on the discharge of the Tocantins River, Southeastern Amazonia. Journal of Hydrology, 283(1): 206-217.

Dooge J C, Bruen M, Parmentier B, 1999. A simple model for estimating the sensitivity of runoff to long-term changes in precipitation without a change in vegetation. Advances in Water Resources, 23(2): $153-163$.

Elfert S, Bormann H, 2010. Simulated impact of past and possible future land use changes on the hydrological response of the Northern German lowland 'Hunte' catchment. Journal of Hydrology, 383(3): 245-255.

Fu C B, Wang Q, 1992. The definition and detection of the abrupt climate change. Scientia Atmospherica Sinica, 16(4): 482-493. (in Chinese)

Hu S, Liu C M, Zheng H X et al., 2012. Assessing the impacts of climate variability and human activities on streamflow in the water source area of Baiyangdian Lake. Journal of Geographical Sciences, 22(5): 895-905.

Jiang D J, 2007. Influence of climate change and land use/land cover change on runoff in the middle and upper reaches of Taoerhe River Basin [D]. Beijing: Graduate University of Chinese Academy of Sciences. (in Chinese)

Jothityangkoon C, Sivapalan M, Farmer D L, 2001. Process controls of water balance variability in a large semi-arid catchment: Downward approach to hydrological model development. Journal of Hydrology, 254(1): 174-198.

Kang S Z, Su X L, Tong L et al., 2004. The impacts of human activities on the water-land environment of the Shiyang River basin, an arid region in Northwest China. Hydrological Sciences Journal, 49(3): 413-427.

Kendall M, 1948. Rank Correlation Methods. New York: Hafner Publishing Company.

Li D F, Tian Y, Liu C M, 2004. Distributed hydrological simulation of the source regions of the Yellow River under environmental changes. Acta Geographica Sinica, 59(4): 565-573. (in Chinese)

Li H B, Luo L F, Wood E F, 2008. Seasonal hydrologic predictions of low-flow conditions over eastern USA during the 2007 drought. Atmospheric Science Letters, 9(2): 61-66.

Li L J, Li B, Liang L Q et al., 2010. Effect of climate change and land use on stream flow in the upper and middle reaches of the Taoer River, northeastern China. Forestry Studies in China, 12(3): 107-115. (in Chinese)

Li L J, Zhang L, Wang $\mathrm{H}$ et al., 2007a. Assessing the impact of climate variability and human activities on streamflow from the Wuding River basin in China. Hydrological Process, 21(25): 3485-3491.

Li K Y, Coe M T, Ramankutty N et al., 2007b. Modeling the hydrological impact of land-use change in West Africa. Journal of Hydrology, 337(3): 258-268.

Li Z, Liu W Z, Zhang X C et al., 2009. Impacts of land use change and climate variability on hydrology in an agricultural catchment on the Loess Plateau of China. Journal of Hydrology, 377(1): 35-42.

Liang K, Liu C M, Liu X M et al., 2013. Impacts of climate variability and human activity on streamflow decrease in a sediment concentrated region in the Middle Yellow River. Stochastic environmental research and risk assessment, 27(7): 1741-1749.

Liang L Q, 2008. Spatial-temporal pattern and evolution mechanism of evapotranspiration in the Taoer River basin [D]. Beijing: Graduate University of Chinese Academy of Sciences. (in Chinese)

Liang L Q, Li L J, Liu Q, 2010. Temporal variation of reference evapotranspiration during 1961-2005 in the Taoer River basin of Northeast China. Agricultural and Forest Meteorology, 150(2): 298-306.

Liu Q, Yang Z, Cui B, 2008. Spatial and temporal variability of annual precipitation during 1961-2006 in Yellow River Basin, China. Journal of Hydrology, 361(3): 330-338.

Luan Z Q, Zhang G X, Deng W et al., 2007. Studies on changes of air temperature and precipitation for last 50 years in Songnen Plain. Chinese Journal of Agrometeorology, 28(4): 355-358. (in Chinese)

Ma C K, Sun L, Liu S Y et al., 2015. Impact of climate change on the streamflow in the glacierized Chu River Basin, Central Asia. Journal of Arid Land, 7(4): 501-513.

Mann H B, 1945. Nonparametric tests against trend. Econometrica: Journal of the Econometric Society, 13: 245-259.

Marengo J A, Tomasella J, Uvo C R, 1998. Trends in streamflow and rainfall in tropical South America: Amazonia, eastern Brazil, and northwestern Peru. Journal of Geophysical Research, 103(D2): 1775-1783.

Milly P C, Dunne K A, 2002. Macroscale water fluxes 2. Water and energy supply control of their inter-annual variability. Water Resource Research, 38(10): 241-249. 
Mitchell J M, Dzerdzeevskii B, Flohn H et al., 1966. Climatic Change, WMO Technical Note, 79. World Meteorological Organization, Geneva.

Najjar R G, 1999. The water balance of the Susquehanna River Basin and its response to climate change. Journal of Hydrology, 219(1): 7-19.

Nash JE, Sutcliffe J, 1970. River flow forecasting through conceptual models (Part I): A discussion of principles. Journal of Hydrology, 10(3): 282-290.

Ren G Y, Wu H, Chen Z H, 2000. Spatial patterns of change trend in rainfall of China. Quarterly Journal of Applied Meteorology, 11(3): 322-330. (in Chinese)

Scanlon B R, Jolly I, Sophocleous M et al., 2007. Global impacts of conversion from natural to agricultural ecosystem on water resources: Quantity versus quality. Water Resources Research, 43(3). doi: 10.1029/2006WR005486.

Schulze R E, 2000. Hydrological responses to land use and climate change: A southern African perspective. AMBIO: A Journal of the Human Environment, 29(1): 12-22.

Serrano A, Mateos V L, Garcia J A, 1999. Trend analysis of monthly precipitation over the Iberian Peninsula for the period 1921-1995. Physics and Chemistry of the Earth, Part B: Hydrology, Oceans and Atmosphere, 24(1): 85-90.

Sneyers R. 1975. Sur l'analyse statistique des s'eries d'observations. WMO Tech Note.

Tang Y, Wang H, Yan D H et al., 2009. Evolutionary regularity of runoff of Nenjiang River Basin in period 1956-2000. Scientia Geographica Sinica, 29(6): 1-12. (in Chinese)

Tomer M D, Schilling K E, 2009. A simple approach to distinguish land-use and climate-change effects on watershed hydrology. Journal of Hydrology, 376(1): 24-33.

Vaze J, Teng J, 2011. Future climate and runoff projections across New South Wales, Australia: Results and practical applications. Hydrological Processes, 25(1): 18-35.

Vorosmarty C J, Green P, Salisbury J et al., 2000. Global water resources: Vulnerability from climate change and population growth. Science, 289(5477): 284-288.

Wang D B, Hejazi M, 2011. Quantifying the relative contribution of the climate and direct human impacts on mean annual stream-flow in the contiguous United States. Water Resources Research, 47(10). doi: 10.1029/ 2010wr010283.

Wang G Q, Zhang J Y, He R M et al., 2008. Runoff reduction due to environmental changes in the Sanchuanhe river basin. International Journal of Sediment Research, 23(2): 174-180.

Wang G X, Zhang Y, Liu G M et al., 2006. Impact of land-use change on hydrological processes in the Maying River basin, China. Science in China Series D: Earth Sciences, 49(10): 1098-1110.

Wei F Y, 1999. Statistical Techniques of Modern Climatic Diagnosis and Forecasting. Beijing: China Meteorological Press, 63-65. (in Chinese)

Yates D N, 1996. WatBal: An integrated water balance model for climate impact assessment of river basin runoff. International Journal of Water Resources Development, 12(2): 121-140.

Yue S, Wang C Y, 2002. Applicability of prewhitening to eliminate the influence of serial correlation on the Mann-Kendall test. Water Resources Research, 38(6). doi: 10.1029/2001wr000861

Zhan S L, Yu Y M, 1994. Methods of Calculating Effect of Soil and Water Conservation Measures. Beijing: China Environmental Science Press. (in Chinese)

Zhang D F, Lin F N, 1999. Study on agricultural eco-geological environment in the Tao'er River Basin. Soil and Environment Sciences, 8(3): 179-183. (in Chinese)

Zhang L, Dawes W R, Walker G R, 2001. The response of mean annual evapotranspiration to vegetation changes at catchment scale. Water Resources Research, 37(3): 701-708.

Zhang L, Hickel K, Dawes W R, 2004. A rational function approach for estimating mean annual evapotranspiration. Water Resources Research, 40. doi: 10.1029/2003WR002710.

Zhang J S, Kang E, Lan Y C et al., 2003. Impact of climate change and variability on water resources in Heihe River Basin. Journal of Geographical Sciences, 13(3): 286-292.

Zhang Q, Xu CY, Tao H, Jiang T et al., 2010. Climate changes and their impacts on water resources in the arid regions: A case study of the Tarim River basin, China. Stochastic Environmental Research and Risk Assessment, 24(3): 349-358.

Zhang S R, Lu X X, 2009. Hydrological responses to precipitation variation and diverse human activities in a mountainous tributary of the lower Xijiang, China. Catena, 77(2): 130-142.

Zhao Y L, 1999. Distribution of Fragile Types of Eco-environment and Their Comprehensive Management in China. Beijing: China Environmental Science Press. (in Chinese) 